\title{
The "incidental" episode of ventricular fibrillation: a case report Fahim H Jafary
}

\author{
Address: Department of Medicine, Section of Cardiology, Aga Khan University Hospital, Karachi, Pakistan
}

Email: Fahim H Jafary - jafary@pobox.com

\author{
Published: 30 August 2007 \\ Received: 13 December 2006 \\ Journal of Medical Case Reports 2007, I:72 doi:10.1 186/1752-1947-1-72 \\ Accepted: 30 August 2007 \\ This article is available from: http://www.jmedicalcasereports.com/content/I/I/72 \\ (C) 2007 Jafary; licensee BioMed Central Ltd. \\ This is an Open Access article distributed under the terms of the Creative Commons Attribution License (http://creativecommons.org/licenses/by/2.0), \\ which permits unrestricted use, distribution, and reproduction in any medium, provided the original work is properly cited.
}

\begin{abstract}
Polymorphic ventricular tachycardia and ventricular fibrillation (VF) carry important prognostic implications, especially in the post myocardial infarction period. However, artifact on the electrocardiographic tracing can mimic VF particularly on routinely recorded rhythm strips in hospitals. Such misinterpretation can lead to expensive (and potentially risky) diagnostic and therapeutic steps. We report on such a case and highlight the need for careful inspection of the tracing.
\end{abstract}

\section{Background}

Arrhythmias may be documented in patients with cardiac or serious medical disorders admitted to units with telemetry monitoring, particularly intensive care wards [1]. Polymorphic ventricular tachycardia and ventricular fibrillation (VF) carry particular prognostic signficance owing to their association with sudden cardiac death. However, artifact on the electrocardiographic tracing can mimic VF particularly on routinely recorded rhythm strips in hospitals. Misinterpretation can lead to expensive (and potentially risky) diagnostic and therapeutic steps. We report on such a case and highlight the need for careful inspection of the tracing.

\section{Case Presentation}

This 45-year-old gentleman was admitted with an acute inferoposterior myocardial infarction. Streptokinase was administered with clinical and electrocardiographic evidence of reperfusion. On the third day of admission, the following rhythm strip (figure 1) was recorded on telemetry after the alarm went off. The patient was asymptomatic and the event was documented as an episode of "transient asymptomatic ventricular fibrillation". The patient was presented on routine rounds the next morning.
Indeed, at first glance the rhythm strip appears to show ventricular fibrillation, which carries significant prognostic and therapeutic implications on the third post myocardial infarction day. On closer review, QRS complexes can be seen "marching through" the tracing (black dots), confirming that the apparent fibrillation is an artifact. Such artifacts can be induced by movement, electrical interference and lose monitor lead connections $[2,3]$. These electrocardiographic artifacts are not uncommon and lead to inappropriate diagnostic and therapeutic steps [4] because they tend to be misinterpreted by physicians, including cardiologists [5].

\section{Conclusion}

Given the widespread use of telemetry monitoring in patients admitted on general medical and speciality services, artifacts on rhythm tracings will inevitably occur. Clinicians should keep such artifacts in mind when interpreting rhythm tracings depicting ventricular fibrillation, particularly when other clinical correlates of this lethal arrhythmia are absent. Careful inspection of the tracing will usually clarify the diagnosis and prevent expensive and potentially risky procedures that would otherwise follow in a genuine case. Further study is warranted to estimate the true prevalence of failure to appre- 


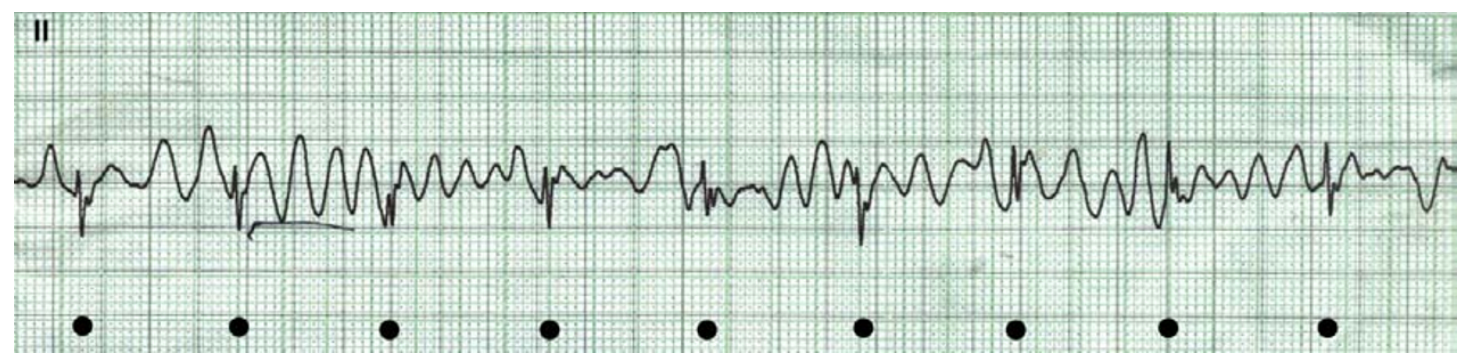

Figure I

"Ventricular fibrillation" - black dots mark QRS complexes "marching through" the artifact in the background.

ciate this artifact amongst physicians of different specialties and levels of experience.

\section{List of Abbreviations}

VF - Ventricular fibrillation.

\section{Competing interests}

The author(s) declare that they have no competing interests.

\section{Authors' contributions}

The author was responsible for the conception and writing of this manuscript.

\section{Acknowledgements}

Written consent was obtained from the patient for publication of this report.

\section{References}

I. Tarditi DJ, Hollenberg SM: Cardiac arrhythmias in the intensive care unit. Semin Respir Crit Care Med 2006, 27:221-229.

2. Srikureja W, Darbar D, Reeder GS: Tremor-induced ECG artifact mimicking ventricular tachycardia. Circulation 2000, I02:1337-1338.

3. Vereckei A: Pseudo-ventricular tachycardia: electrocardiographic artefact mimicking non-sustained polymorphic ventricular tachycardia in a patient evaluated for syncope. Heart 2004, 90:81

4. Knight BP, Pelosi F, Michaud GF, Strickberger SA, Morady F: Clinical consequences of electrocardiographic artifact mimicking ventricular tachycardia. N Engl] Med I999, 34 I: I 270- I 274.

5. Knight BP, Pelosi F, Michaud GF, Strickberger SA, Morady F: Physician interpretation of electrocardiographic artifact that mimics ventricular tachycardia. Am J Med 200 I, I l 0:335-338.
Publish with Bio Med Central and every scientist can read your work free of charge

"BioMed Central will be the most significant development for disseminating the results of biomedical research in our lifetime. "

Sir Paul Nurse, Cancer Research UK

Your research papers will be:

- available free of charge to the entire biomedical community

- peer reviewed and published immediately upon acceptance

- cited in PubMed and archived on PubMed Central

- yours - you keep the copyright
BioMedcentral 